\title{
A novel approach for quantifying particulate matter distribution on leaf surface by combining SEM and object-based image analysis
}

\author{
Jingli Yan ${ }^{\mathrm{a}, \mathrm{b}, 1}$, Lin Lin ${ }^{\mathrm{a}, \mathrm{b}, 1}$, Weiqi Zhou ${ }^{\mathrm{a}, *}$, Keming Ma ${ }^{\mathrm{a}, *}$, Steward T.A. Pickett ${ }^{\mathrm{c}}$ \\ a State Key Laboratory of Urban and Regional Ecology, Research Center for Eco-Environmental Sciences, Chinese Academy of Sciences, Beijing 100085, China \\ b University of Chinese Academy of Sciences, Beijing 100049, China \\ c Cary Institute of Ecosystem Studies, Box AB, Millbrook, NY 12545, USA
}

\section{A R T I C L E I N F O}

\section{Article history:}

Received 21 July 2015

Received in revised form 20 November 2015

Accepted 24 November 2015

Available online 5 December 2015

Keywords:

PM capture

SEM micrograph

Particle size and shape

Urban vegetation

Ecosystem service

\begin{abstract}
A B S T R A C T
Most methods for assessing the loading of particles on plant leaf surfaces involve a cumbersome manual step, and hence are slow to employ. Furthermore, they yield results that are summative, representing total number of particles or total volume or weight of particles in standardized size fractions. Here, we present a novel approach that cannot only accurately quantify the number of particles, but also their size and shape. In addition, the method we present replaces the manual measurement of the particles on leaf surfaces with an automated step. We applied the well-developed object-based image analysis technique to scanning electronic microscope (SEM) micrographs of tree leaf, and tested this approach for replicate SEM micrographs of a common urban tree species. We demonstrated that: 1 ) this new method automatically identifies the number of particles, as well as their size and shape, in contrast to the commonly used microscopic inspection approach that can only measure the number of particles; and 2) this method achieved similar overall accuracy to that of microscopic inspection (92.17\% versus 95.53\%), but microscopic inspection takes fourteen times longer. It is expected that the difference in efficiency would be more significant with the increase of micrograph numbers, because micrographs can be batch processed with object-based classification. With the greatly increased efficiency and the ability of the proposed method to capture new variables about particle shape and complexity, this method can facilitate comparative research on the adsorption capacities of different plant species, and potentially identifying the source apportionment of particulate matters based on their morphological characteristics, which may provide insights for species selection for pollutant reduction.
\end{abstract}

(c) 2015 Elsevier Inc. All rights reserved.

\section{Introduction}

Particulate matter (PM) can reduce the visibility in the atmosphere, change its radiation properties (Han et al., 2012), and alter the urban thermal environment. Importantly, particulate matter $\left(\mathrm{PM}_{10}\right)$ can seriously threaten human health by entering into the respiratory tract (Sierra-Vargas \& Teran, 2012), and with $\mathrm{PM}_{2.5}$ even accumulating in bronchiole and alveoli. World Health Organization (WHO) estimated that annually $5.3 \%$ of premature deaths worldwide, about 3.1 million people, are attributable to air pollution in 2009.

PM capture from the atmosphere is an important ecosystem service of urban vegetation. The adsorption of PM on plants includes two modes. First, on account of the tremendous leaf surface area and complex leaf structure, the vegetation can intercept and retain particles on leaf surfaces, even immobilize some particles in cuticular wax

\footnotetext{
* Corresponding authors at: Shuangqing Road 18, Haidian District, Beijing 100085 China.

E-mail addresses: wzhou@rcees.ac.cn (W. Zhou), mkm@rcees.ac.cn (K. Ma).

1 J. Yan and L. Lin contributed equally to this work.
}

(Terzaghi et al., 2013). Second, particles are deposited on the leaf surface temporarily and can be re-suspend or fall to the ground when air flow changes. There is extensive research estimated the amount and monetary value of particle retention (McDonald et al., 2007; Nowak, Hirabayashi, Bodine, \& Greenfield, 2014).

Different species have distinct PM capture properties because of their physiological, chemical, and morphological features, and will significantly affect the value of this ecosystem service. Therefore, it is necessary to quantify how many particles, of what sizes, and at what rates a species can retain them. Currently, the commonly used methods for quantifying PM retention are leaf washing with water or solvent or both; exposure to experimental particles in wind tunnels, and microscopic observation.

The leaf washing method, in which leaves are washed with solvent that is then filtered through different pore diameters, is used to quantify the differences of PM retention among species (Beckett, Freer Smith, \& Taylor, 2000a; Freer-Smith, Beckett, \& Taylor, 2005; Freer-Smith, Holloway, \& Goodman, 1997). Although it is a simple process and divides PM into specific diameter classes, it may underestimate the amount of particles on leaves because water-soluble ions account for approximately $45 \%$ of the total aerosol mass in some samples (Li et al. 


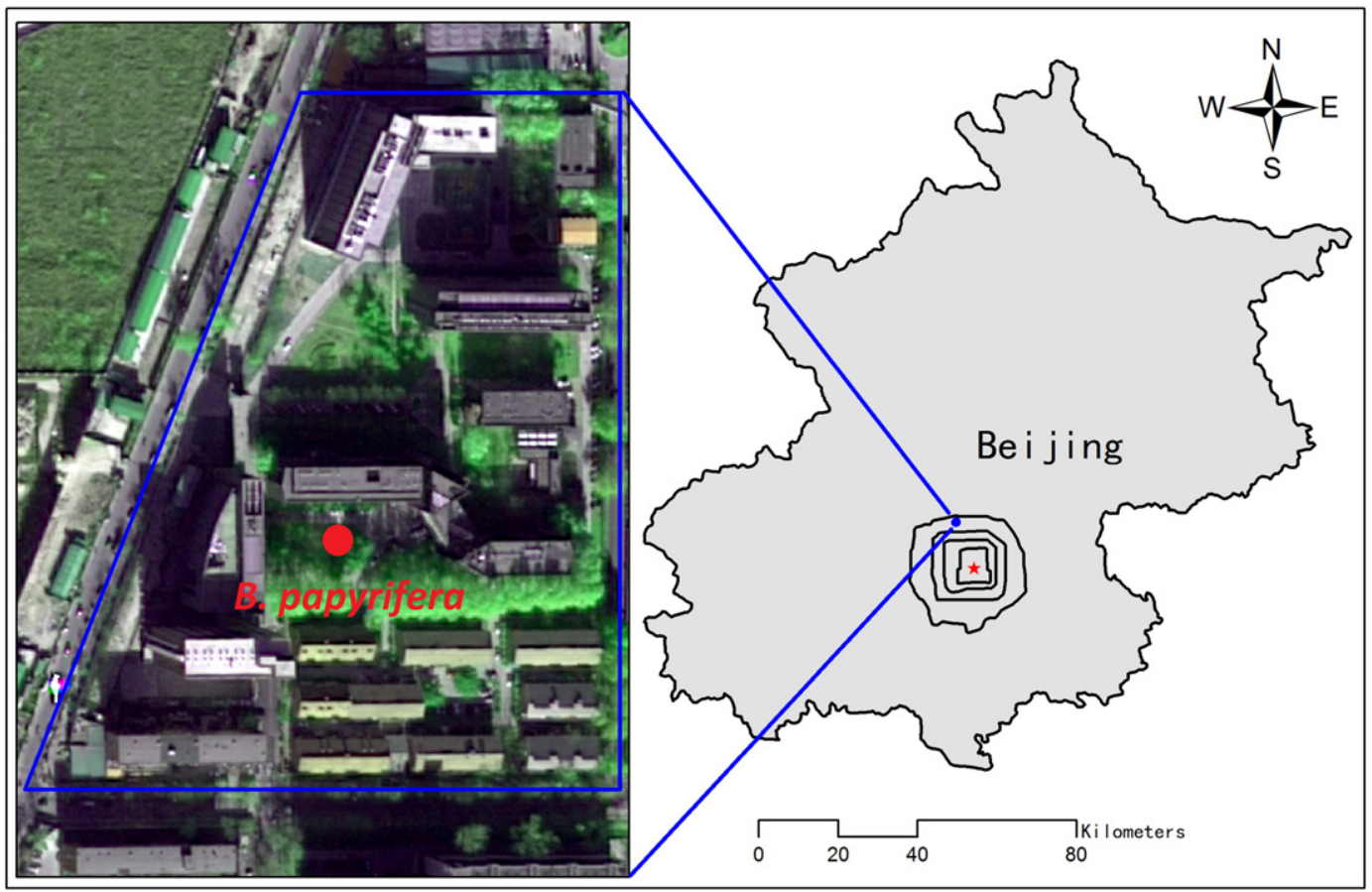

Fig. 1. Sampling location (B. papyrifera) at RCEES, Chinese Academy of Sciences, located between the 4th and 5th ring road in Beijing, China.

2012). Therefore, the leaf washing method can only separate and quantify the insoluble fraction of the adsorbed PM.

The wind tunnel method can precisely control wind velocity, pollutant concentration and the diameter of particulate matter, so it can simulate particle retention with a precision that is hard to replicate in the field. However, because of the cost, the tunnel size usually is small, so experiments are only conducted with small subsamples of branches. Moreover, the particles from the aerosol generator are single compounds of uniform size, which is unlike the mixture of compounds and sizes that obtain under field conditions (Beckett, Freer Smith, \& Taylor, 2000b; Räsänen et al., 2013; Reinap, Wiman, Svenningsson, \& Gunnarsson, 2009).

Microscopy can be used to measure the particle size distribution and number of particles (Weber, Kowarik, \& Saumel, 2014). The scanning electron microscope (SEM) was commonly used to quantify the particles captured by leaves visually, and identify the types of particulate matter. Its advantages are an intuitive observation strategy, the capacity for great magnification, a large depth of field, and the ability to analyze the elemental composition of particulate matter with an Energy Disperse Spectroscopy (EDS) attached to the microscope (Kocic, Spasic, Urosevic, \& Tomasevic, 2014). However, one of the main obstacles to fast quantification of adsorbed particles by microscopy is PM recognition. The most commonly used method for SEM micrographs is to identify and count PM by visual inspection, which is too subjective and time consuming for common use. Some studies obtain quantity and particle size using ImageJ software (Ottelé, Van Bohemen, \& Fraaij, 2010) or ImagePro-Plus
(Baronea \& Zhu, 2008), but the analysis is difficult when the leaf structure is complex. In addition, the rate of information acquisition from microscopy is slow, limiting the amount of data available for further analysis.

Therefore, an automatic particle identification method based on SEM images, and using the technology of object-based image analysis is presented. This new approach enables rapid identification of the number of particles and their size distribution using objective features and methods rather than subjective visual inspection. It also provides abundant size and shape information, which other methods cannot. The method we propose will permit automatic recognition of particulate matter on microscopic images and facilitate the study of particle capture by vegetation and the development of pollution indicators of vegetation.

\section{Materials and methods}

\subsection{Study area}

The sampling site is located on the campus of the Research Center for Eco-environmental Sciences (RCEES) ( $\left.40^{\circ} 0^{\prime} 26.24^{\prime \prime} \mathrm{N}, 116^{\circ} 20^{\prime} 13.21^{\prime \prime} \mathrm{E}\right)$, of the Chinese Academy of Sciences, Beijing, China (Fig. 1). Beijing has been listed as one of the top ten polluted cities in the world because of its dense population and rapid urbanization. The annual PM2.5 concentration was $85.9 \mu \mathrm{g} / \mathrm{m}^{3}$ in 2014 according to the Beijing Environmental
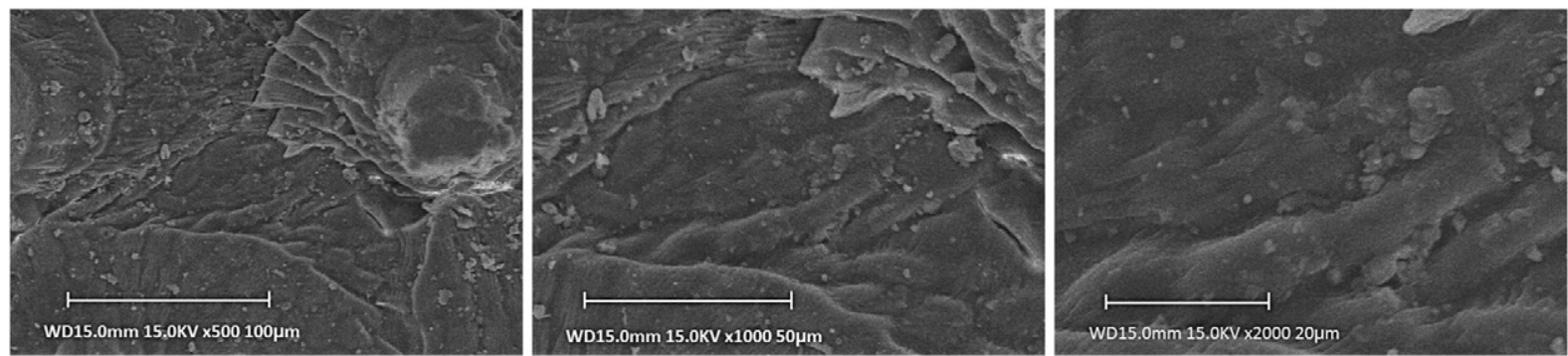

Fig. 2. The SEM micrographs of B. papyrifera at different magnifications. From left to right, $500 \times, 1000 \times$, and $2000 \times$. 


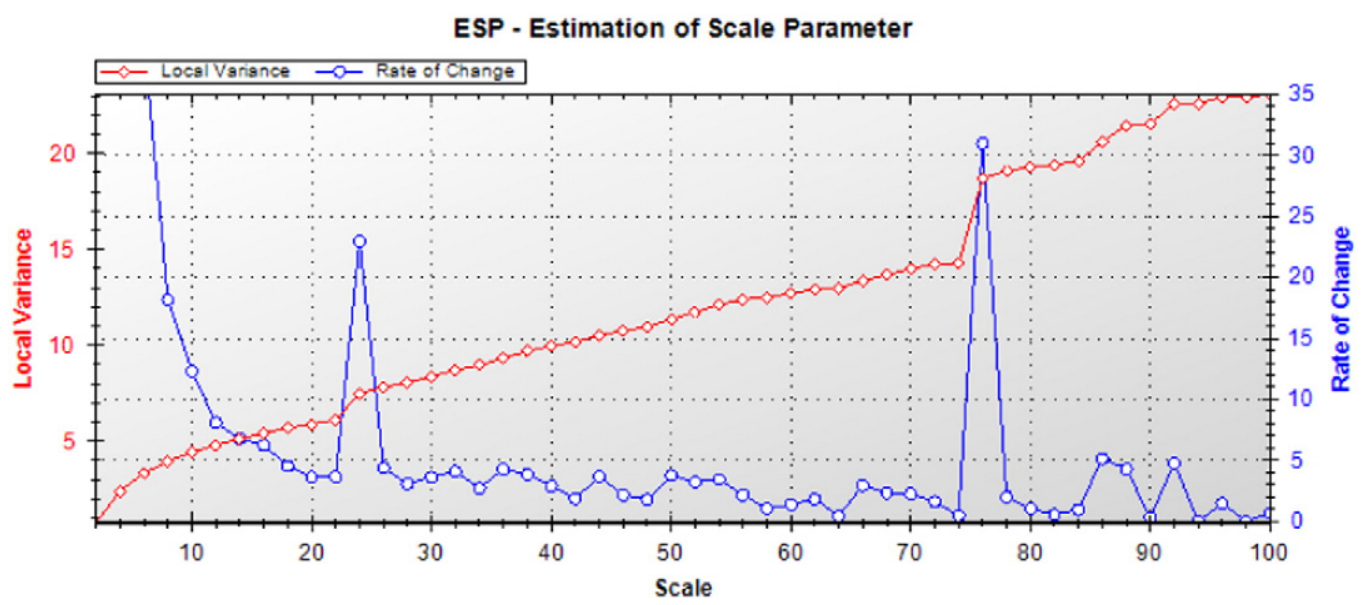

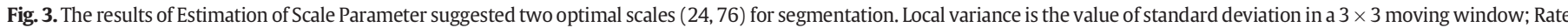
of Change $=[(\mathrm{L}-(\mathrm{L}-1)) /(\mathrm{L}-1)] \times 100$, where $\mathrm{L}=$ local variance at target level, $\mathrm{L}-1=$ local variance at next lower level.
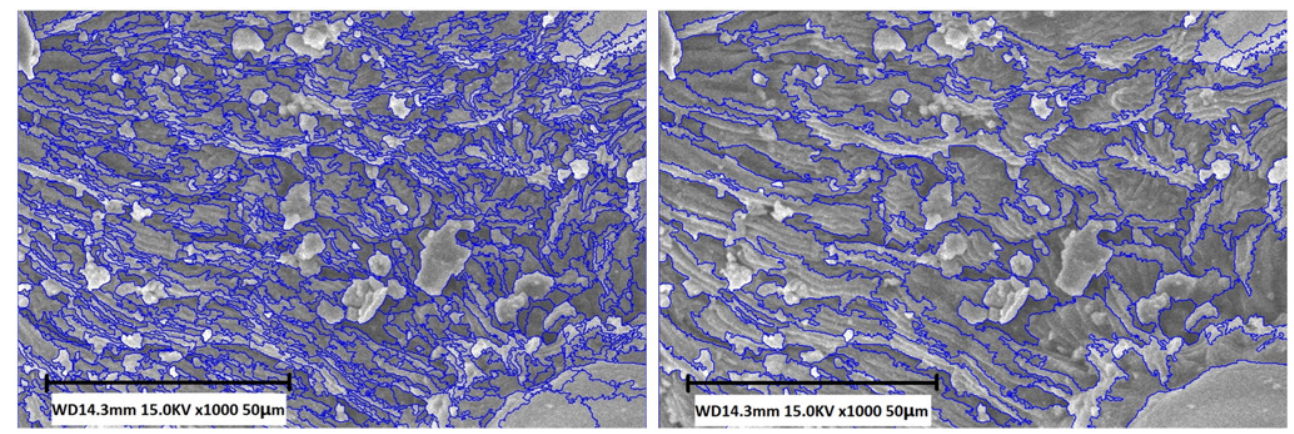

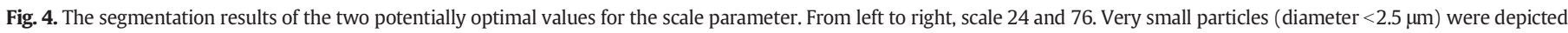
better at scale 24 .

Protection Bureau. The campus is located at the transition area from urban to sub-urban, with dense residential areas and university campuses being the main land use types. Because the paper presents a proof of concept for a new method, we use sample leaves from a common tree species typical of the Beijing region. The test tree located in a small area of mixed vegetation in the center of the RCEES campus, and is more than $50 \mathrm{~m}$ away from four-lane road. There are no polluting industries or power plants within $5 \mathrm{~km}$; however, a large site was under construction to the northwest of the campus.

\subsection{Sampling and sample preparation}

We chose Broussonetia papyrifera (L.), a common tree species in Beijing to test the approach. Five mature and healthy leaves at the height of $2 \mathrm{~m}$ were cut with scissors from one tree. The leaves were stored in hermetic bags to prevent further contamination or particle fall after collection. We randomly selected one leaf from the five sampled leaves, and collected a $1 \mathrm{~cm}^{2}$ sample between the leaf edge and midrib on a clean and closed operation desk. The sample was then mounted on an aluminum stub, using double-sided sticky tape, and was coated with a thin conductive film of gold in an ion sputter coater. Coated specimen then was photographed under a Hitachi S-3000N scanning electron microscope at an accelerating voltage of $15 \mathrm{KV}$.

\subsection{SEM measurements}

We randomly selected three spots on the $1 \mathrm{~cm}^{2}$ sample, and three SEM micrographs with different magnifications $(500 \times, 1000 \times$, $2000 \times$ ) were taken for each spot (Fig. 2). Based on visual inspection and comparison, we chose micrographs of $1000 \times$ for the subsequent analysis, considering the resolution and field of view. Therefore, three SEM micrographs with magnification of $1000 \times$ were analyzed in the

Table 1

The summary of the 24 candidate features used in Classification and regression trees.

\begin{tabular}{llc}
\hline Feature name & Description & Rel. imp \\
\hline Mean band & Mean intensity of an image object of a image band & 51.74 \\
Brightness & Mean value of all image bands ${ }^{\text {a }}$ & 51.74 \\
SD & Standard deviations of a image band & 98.16 \\
Hue & Mean of hue, one of three color components & 0 \\
Saturation & Mean of saturation, one of three color components & 0 \\
Intensity & Mean of intensity, one of three color components & 51.74 \\
Elliptic fit & How well an image object fits into an ellipse & 0 \\
Rectangular fit & How well an image object fits into a rectangle & 0 \\
Area & The number of pixels & 16.52 \\
Roundness & How similar an image object is to an ellipse & 18.70 \\
Compactness & Similar to border index, but is based on area & 39.40 \\
Shape index & The smoothness of the boundary of an image object & 26.06 \\
Border index & How jagged an image object is & 25.06 \\
Length/width & The ratio of length and width & 0 \\
Length & The length of an image object & 10.62 \\
Width & The width of an image object & 6.22 \\
Density & The spatial distribution of the pixels of an image object & 100.00 \\
Asymmetry & Describes the relative length of an image object & 0 \\
GLCM-H & GLCM homogeneity & 0 \\
GLCM-C & GLCM contrast & 0 \\
GLCM-D & GLCM dissimilarity & 0 \\
GLCM-E & GLCM entropy from & 17.37 \\
GLCM-A & GLCM angular 2nd moment & 6.75 \\
GLCM-M & GLCM mean & 59.17 \\
\hline
\end{tabular}

Rel.imp means relative importance; GLCM (Gray-level Co-occurrence Matrix) is a tabulation of how often different combinations of pixel gray levels occur in a scene, which was calculated in eCognition developer.

a SEM micrograph has only one band. 


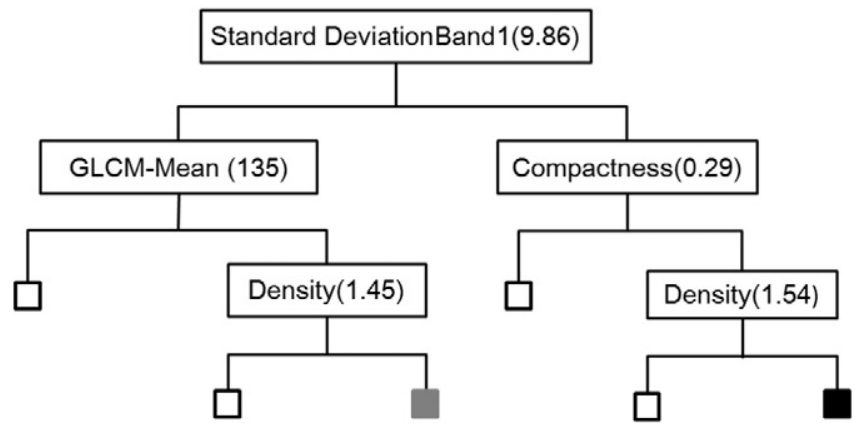

Fig. 5. The optimal decision tree resulted from the Classification and regression trees The values in parenthesis are thresholds used in the ruleset, and values higher than the threshold go to the right. Solid black square means "above average" risk, hollow square means "below average" risk, and hatched square means moderate risk.

study, and the real leaf size for one micrograph was calculated as $1.23 \times 10^{4} \mu \mathrm{m}^{2}$ based on the scale bar.

\subsection{SEM micrograph analysis}

We developed a new approach to quantify the particles load on leaf surfaces based on SEM micrographs, using an object-based image analysis technique. This approach includes three steps. First, we used a multi-resolution segmentation algorithm to segment SEM micrographs into image objects (Baatz \& Schäpe, 2000; Benz, Hofmann, Willhauck, Lingenfelder, \& Heynen, 2004). Then we used classification and Regression Tree (CART) to generate classification rulesets based on the selected training samples. Finally, we applied the ruleset based classification to the entire micrographs for particle matter identification and characterization. Since the three SEM micrographs were taken under the same conditions and at the same magnifications $(1000 \times)$, the developed ruleset was applied to all three micrographs.

\subsubsection{Segmentation}

Segmentation is crucial to image object analysis. The multi-resolution segmentation (MRS) algorithm embedded in eCognition DeveloperTM software was applied to generate image objects. The algorithm consecutively merges pixels or existing image objects into larger objects based on relative homogeneity within the merged object (Baatz \& Schäpe, 2000). Three key parameters, scale, shape and compactness can be set to determine the degree of homogeneity (Anders, Seijmonsbergen, \& Bouten, 2011). A larger value of the scale parameter results in larger objects. The weight of shape equals 1 minus that of color. Generally, a relatively high weight is set for color to generate more meaningful objects (Laliberte et al., 2004; Pu \& Landry, 2012). The parameter compactness determines smoothness of the resultant objects.

We used the Estimation of Scale Parameter (ESP) (Drăguț, Tiede, \& Levick, 2010; Drăguţ, Csillik, Eisank, \& Tiede, 2014) to help determine the value of the scale parameter. ESP provides a relatively efficient and objective means to choose an optimal value of the scale parameter. The results suggested two optimal segmentation scales (24 and 76) for different classes. Based on further visual inspection, we found the scale of 24 is better to describe leaf particle boundaries (Fig. 3). In addition, at this scale, the very small particles (diameter $<2.5 \mu \mathrm{m}$ ) could be depicted well (Fig. 4). Therefore, we chose the scale of 24 , and set 0.2 and 0.5 for shape and compactness, respectively.

\subsubsection{Classification}

Classification and regression trees (CART) from Salford system were used for classification. CART (Breiman, Friedman, Olshen, \& Stone, 1984; Clark \& Pregibon, 1992) is a non-parametric classification method which uses learning samples to generate accurate and reliable predictive models (De'ath \& Katharina, 2000). The advantages of CART include, for example, 1) feature reduction and ranking; 2) no need for selection of variables in advance; 3 ) generation of rules with associated features; and 4) efficiency (Laliberte, Browning, \& Rango, 2012).

With CART, we first randomly selected 50 training samples visually for each SEM micrograph, for a total of 150 samples. We then identified 24 object features that were potentially useful for classification based on the entire samples. These included features of spectrum, shape and texture (Table 1). We then ran CART with the samples, using the identified features as candidate features. The resultant optimal decision tree included six nodes and four features, that is standard deviation, compactness, density, and Gray-level co-occurrence Matrix-Mean (GLCM-M) (Fig. 5), with Relative Cost (RC) of 0.105 and Rate of Change (ROC) of 0.988 , indicating reliable performance of the model. The value of $\mathrm{RC}$ ranges from 0 to 1 , with 0 meaning a perfect model with no error, and 1 meaning random guessing. Similarly, the value of ROC ranges from 0 to 1, with higher values suggesting better performance. Finally, we applied the ruleset generated from CART to classify the entire micrographs.
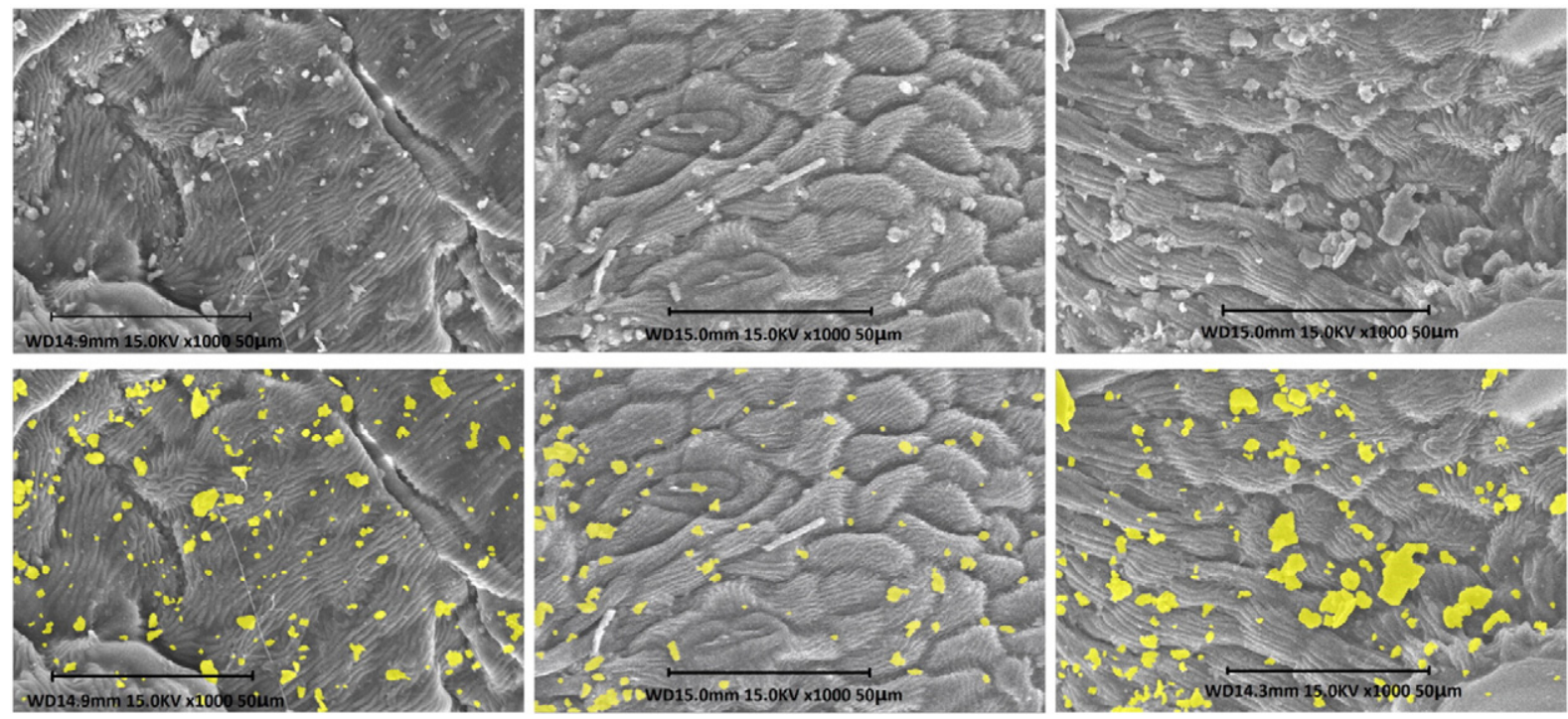

Fig. 6. The SEM micrographs of B. papyrifera (top row) and the classification results of the same micrographs (bottom row); the yellow patches are the classified PM. 
Table 2

The accuracies of classifications.

\begin{tabular}{|c|c|c|c|c|c|c|c|}
\hline SEM micrograph & Reference & Microscopic inspection & NVI & Accuracy (\%) & Object-based classification & NAC & Accuracy (\%) \\
\hline 1 & 146 & 159 & 139 & 95.20 & 154 & 135 & 92.47 \\
\hline 2 & 89 & 97 & 87 & 97.75 & 96 & 83 & 93.26 \\
\hline 3 & 212 & 232 & 201 & 94.81 & 216 & 194 & 91.51 \\
\hline Total & 447 & 488 & 427 & 95.53 & 466 & 412 & 92.17 \\
\hline
\end{tabular}

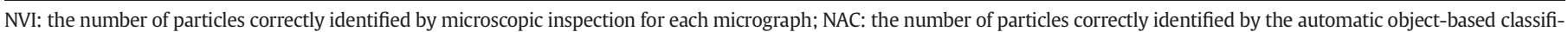
cation for each micrograph.

Table 3

The summary of PM in terms of quantity and area.

\begin{tabular}{lllll}
\hline $\begin{array}{l}\text { SEM } \\
\text { micrograph }\end{array}$ & $\begin{array}{l}\text { Particle } \\
\text { number } / \mathrm{cm}^{2}\end{array}$ & $\begin{array}{l}\text { Average } \\
\text { number } / \mathrm{cm}^{2}\end{array}$ & $\begin{array}{l}\text { Area } \\
\text { percent(\%) }\end{array}$ & $\begin{array}{l}\text { Average } \\
\text { percent(\%) }\end{array}$ \\
\hline 1 & $1.39 \times 10^{6}$ & & 6.89 & \\
2 & $0.87 \times 10^{6}$ & $1.57 \times 10^{6}$ & $\begin{array}{r}4.81 \\
7.60\end{array}$ \\
3 & $1.95 \times 10^{6}$ & & 11.09 & \\
\hline
\end{tabular}

\subsubsection{Accuracy assessment}

We assessed the accuracies of visual inspection and automatic identification. Two experts worked together on the counting of particles for the three micrographs, which were used as the reference for accuracy assessment. To minimize the errors, we labeled each particle as it was counted to avoid missing or double counting. With the microscopic inspection approach, an expert who is proficient in visual inspection counted the number of the particles. We also recorded the time the expert spent on each SEM micrograph. The accuracy was calculated by dividing the total number of particles identified as the reference by the number of particles correctly identified by visual Inspection, or by the automatic classification approach.

\section{Results and discussion}

The automatic approach accurately identified the PM on the leaves (Fig. 6). The number of PM on SEM micrographs varied from 96 to 216 according to the object-based classifications. The accuracies of the object-based approach were nearly the same, ranging from $91.51 \%$ to 93.26\% across the three micrographs (Table 2), suggesting that the automatic identification method yields stable results. The overall accuracy of the new approach was $92.17 \%$, slightly lower than the $95.53 \%$ of microscopic inspection (Table 2). However, the new approach is much more efficient than visual inspection. On average, visual inspection took 13.2 min to count the number of particles for each SEM micrograph, approximately fourteen times longer than the automatic approach ( $0.9 \mathrm{~min}$, the average time of ruleset execution). Based on classification results of the automatic approach, we created a new indicator, percentage cover of particles (PC), to assess the efficiency of PM captured by a micrograph, in addition to the frequently used indicator, particle number per unit area (PN). PC was defined as the percentage of the total area covered by all particles on a SEM micrograph, and PN was the average particle number on leaves within one square centimeters. The average PN is $1.57 \times 10^{6} / \mathrm{cm}^{2}$, and the average PC is $7.60 \%$ (Table 3).

More importantly, with the new approach, we can collect a great deal of information about the size and shape characteristics of the particles captured by the leaves (Fig. 7). Most of the characteristics, such as the area, compactness, roundness, and shape index of the particles that we described in Fig. 7 could be generated in eCognition developer. The characteristics can tell the differences in particle retention between plant species, and also may have important implications for human health, provide insights on the sources of the particles (Makkonen, Hellén, Anttila, \& Ferm, 2010; McDonald \& Biswas, 2012; Slezakova, Pires, Pereira, Martins, \& Alvim-Ferraz, 2008).

Previous studies have also applied image processing software, such as ImageJ, to extract particles based on a binarization algorithm to measure particle number and size (Ottelé et al., 2010; Song et al., 2015). The major difference between the object-based approach and the Image method was that Image J requires the image to be a "binary" image (Ottelé et al., 2010), in which an optimal threshold must firstly be set in order to discriminate the particles from the background before segmentation. Therefore the difficulty increases when ImageJ was applied to leaves with complex surface structure, and the particle boundaries were less reliable than that derived from object-based classifications. The leaves of $B$. papyrifera trees, used in this study, are representative of tree species having relatively complex leaf structure because of
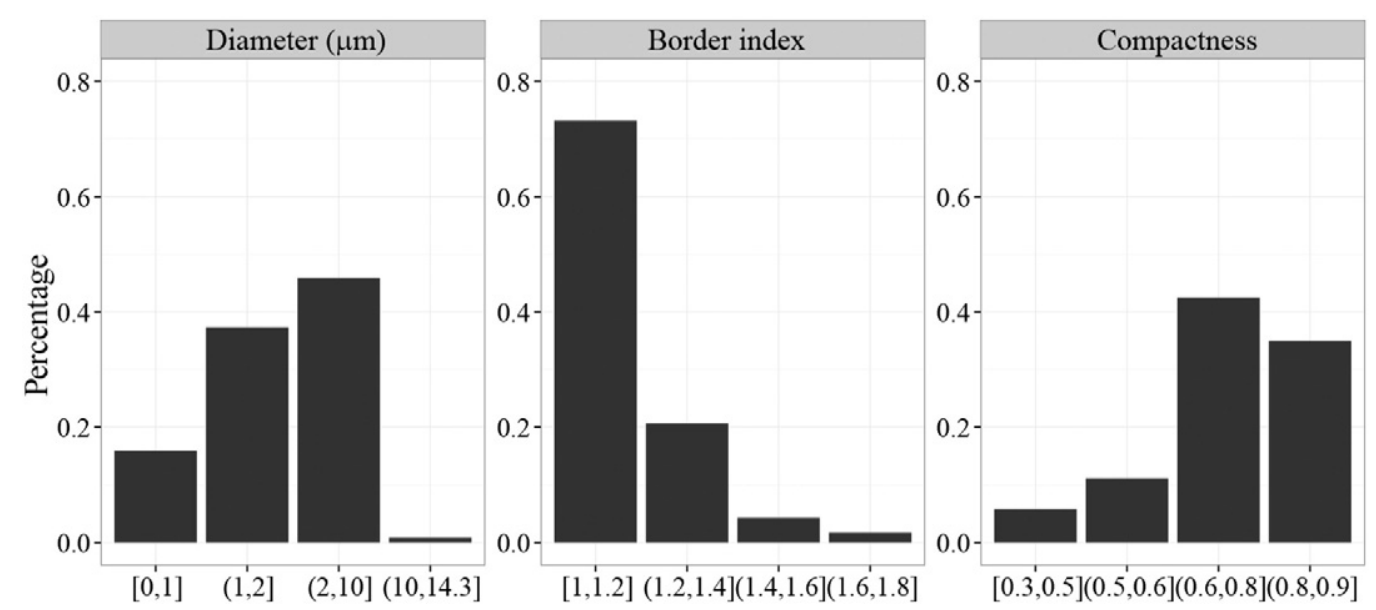

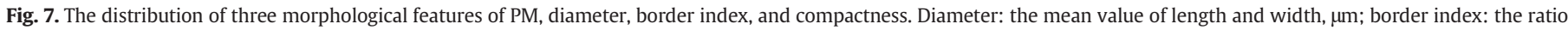

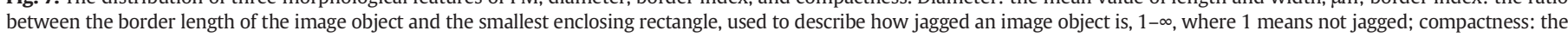
area ratio of the polygon to the circle with the same perimeter, $0-1$, where 1 indicates a circle. 
rough leaf surface and cuticular hairs. Therefore, we would expect that this new approach can be applied to a broad range of leaves from different plant species. For leaves with much more complex surface structure, we can also apply this approach, but would use SEM micrographs with greater magnifications.

\section{Conclusion}

This paper presents a novel approach based on an object-based image analysis technique that can automatically quantify PM on tree leaves based on SEM micrographs. We exemplified this approach by analyzing SEM micrographs of an urban tree species. We found that: 1) this new method automatically identifies the number of particles, as well as their size and shape, in contrast to the commonly used microscopic inspection approach that can only measure the number of particles; and 2) this method achieved much higher efficiency (more than fourteen times faster) with similar overall accuracy to that of microscopic inspection (92.17\% versus 95.53\%). It is expected that the difference in efficiency would be more significant with the increase of the field of view. 3) the new approach also can obtain plenty of data on size and shape characteristics, which are crucial to understand the deposition of PM, and even identify its sources. With the greatly increased efficiency and the addition of new variables about particle morphology and complexity, this method can facilitate comparative research on the PM capturing efficiencies of different plant species, and potentially identifying the source apportionment of particulate matters based on their morphological characteristics, which may provide insights for species selection for specific pollutant reduction.

\section{Acknowledgments}

This study was supported by the "One-Hundred Talented" program of the Chinese Academy of Sciences, and National Science Foundation of China (Key Program: No. 41430638), and the project "Major Special Project-The China High-Resolution Earth Observation System". We thank Dr. Lijian Han for his comments, and Pengfei Zhao for visual inspection of particles on SEM micrographs.

\section{References}

Anders, N. S., Seijmonsbergen, A. C., \& Bouten, W. (2011). Segmentation optimization and stratified object-based analysis for semi-automated geomorphological mapping. Remote Sensing of Environment, 115, 2976-2985.

Baatz, M., \& Schäpe, A. (2000). Multiresolution segmentation-an optimization approach for high quality multi-scale image segmentation. In J. Strobl, T. Blaschke, \& G. Griesebner (Eds.), Angew. Geogr. Info.verarbeitung (pp. 12-23). Heidelberg: Wichmann-Verlag.

Baronea, T. L., \& Zhu, Y. F. (2008). The morphology of ultrafine particles on and near major freeways. Atmospheric Environment, 42, 6749-6758.

Beckett, K. P., Freer Smith, P., \& Taylor, G. (2000a). Effective tree species for local air quality management. Journal of Arboriculture, 26, 12-19.

Beckett, K. P., Freer Smith, P., \& Taylor, G. (2000b). Particulate pollution capture by urban trees: Effect of species and windspeed. Global Change Biology, 6, 995-1003.

Benz, U. C., Hofmann, P., Willhauck, G., Lingenfelder, I., \& Heynen, M. (2004). Multiresolution, object-oriented fuzzy analysis of remote sensing data for GIS-ready information. ISPRS Journal of Photogrammetry and Remote Sensing, 58(3-4), 239-258.

Breiman, L., Friedman, J. H., Olshen, R. A., \& Stone, C. J. (1984). Classification and Regression Trees. Belmont, CA: Wadsworth International Group.

Clark, L. A., \& Pregibon, D. (1992). In J. M. Chambers, \& T. J. Hastie (Eds.), Tree-based models in statistical models (pp. 377-420).
De'ath, G., \& Katharina, E. (2000). Fabricius classification and regression trees: A powerful yet simple technique for ecological data analysis. Ecology, 81, 3178-3192.

Drăguţ, L., Csillik, O., Eisank, C., \& Tiede, D. (2014). Automated parameterisation for multiscale image segmentation on multiple layers. ISPRS Journal of Photogrammetry and Remote Sensing, 88, 119-127.

Drăguţ, L., Tiede, D., \& Levick, S. R. (2010). ESP: a tool to estimate scale parameter for multiresolution image segmentation of remotely sensed data. International Journal of Geographical Information Science, 24(6), 859-871.

Freer-Smith, P., Holloway, S., \& Goodman, A. (1997). The uptake of particulates by an urban woodland: Site description and particulate composition. Environmental Pollution, 95, 27-35.

Freer-Smith, P. H., Beckett, K. P., \& Taylor, G. (2005). Deposition velocities to Sorbus aria, Acer campestre, Populus deltoides X trichocarpa 'Beaupre', Pinus nigra and X Cupressocyparis leylandii for coarse, fine and ultra-fine particles in the urban environment. Environmental Pollution, 133, 157-167.

Han, S. Q., Bian, H., Zhang, Y. F., Wu, J. H., Wang, Y. M., Tie, X. X., ... Yao, Q. (2012). Effect of aerosols on visibility and radiation in spring 2009 in Tianjin, China. Aerosol and Air Quality Research, 12, 211-217.

Kocic, K., Spasic, T., Urosevic, M. A., \& Tomasevic, M. (2014). Trees as natural barriers against heavy metal pollution and their role in the protection of cultural heritage. Journal of Cultural Heritage, 15, 227-233.

Laliberte, A. S., Browning, D. M., \& Rango, A. (2012). A comparison of three feature selection methods for object-based classification of sub-decimeter resolution UltraCam-L imagery. International Journal of Applied Earth Observation and Geoinformation, 15, 70-78.

Laliberte, A. S., Rango, A., Havstad, K. M., Paris, J. F., Beck, R. F., McNeely, B., \& Gonzalez, D. (2004). Object-oriented image analysis for mapping shrub encroachment from 1937 to 2003 in southern New Mexico. Remote Sensing of Environment, 93, 198-210.

Li, X., Wang, L., Wang, Y., Wen, T., Yang, Y., Zhao, Y., \& Wang, Y. (2012). Chemical composition and size distribution of airborne particulate matters in Beijing during the 2008 Olympics. Atmospheric Environment, 50, 278-286.

Makkonen, U., Hellén, H., Anttila, P., \& Ferm, M. (2010). Size distribution and chemical composition of airborne particles in south-eastern Finland during different seasons and wildfire episodes in 2006. Science of the Total Environment, 408, 644-651.

McDonald, A. G., Bealey, W. J., Fowler, D., Dragosits, U., Skiba, U., Smith, R. I., ... Nemitz, E. (2007). Quantifying the effect of urban tree planting on concentrations and depositions of PM10 in two UK conurbations. Atmospheric Environment, 41, 8455-8467.

McDonald, R., \& Biswas, P. (2012). A methodology to establish the morphology of ambient aerosols. Journal of the Air \& Waste Management Association, 54(9), 1069-1078.

Nowak, D. J., Hirabayashi, S., Bodine, A., \& Greenfield, E. (2014). Tree and forest effects on air quality and human health in the United States. Environmental Pollution, 193, 119-129.

Ottelé, M., Van Bohemen, H. D., \& Fraaij, A. L. A. (2010). Quantifying the deposition of particulate matter on climber vegetation on livingwalls. Ecological Engineering, 36, 154-162.

Pu, R. L., \& Landry, S. (2012). A comparative analysis of high spatial resolution IKONOS and WorldView-2 imagery for mapping urban tree species. Remote Sensing of Environment, 124, 516-533.

Räsänen, J. V., Holopainen, T., Joutsensaari, J., Ndam, C., Pasanen, P., Rinnan, Å., \& Kivimäenpää, M. (2013). Effects of species-specific leaf characteristics and reduced water availability on fine particle capture efficiency of trees. Environmental Pollution, 183, 64-70.

Reinap, A., Wiman, B. L. B., Svenningsson, B., \& Gunnarsson, S. (2009). Oak leaves as aerosol collectors: Relationships with wind velocity and particle size distribution. Experimental results and their implications. Trees-Structure and Function, 23, 1263-1274.

Sierra-Vargas, M. P., \& Teran, L. M. (2012). Air pollution: Impact and prevention. Respirology, 17, 1031-1038.

Slezakova, K., Pires, J. C. M., Pereira, M. C., Martins, F. G., \& Alvim-Ferraz, M. C. (2008). Influence of traffic emissions on the composition of atmospheric particles of different sizes-part 2: SEM-EDS characterization. Journal of Atmospheric Chemistry, 60, 221-236.

Song, Y. S., Maher, B. A., Li, F., Wang, X. K., Sun, X., \& Zhang, H. X. (2015). Particulate matter deposited on leaf of five evergreen species in Beijing, China: Source identification and size distribution. Atmospheric Environment, 105, 53-60.

Terzaghi, E., Wild, E., Zacchello, G., Cerabolini, B. E. L., Jones, K. C., \& Di Guardo, A. (2013). Forest filter effect: Role of leaves in capturing/releasing air particulate matter and its associated PAHs. Atmospheric Environment, 74, 378-384.

Weber, F., Kowarik, I., \& Saumel, I. (2014). Herbaceous plants as filters: Immobilization of particulates along urban street corridors. Environmental Pollution, 186, 234-240. 